\title{
Operational Limits in Processes with Water, Salt, and Short-Chain Alcohol Mixtures as Aqueous Two-Phase Systems and Problems in Its Simulation
}

\author{
Alejandro Gomis, Jorge García-Cano, Alicia Font, and Vicente Gomis*
}

Cite This: Ind. Eng. Chem. Res. 2021, 60, 2578-2587

ABSTRACT: The low critical solution temperature (LCST) and minimum salt concentration that cause phase splitting in water and short-chain alcohol mixtures were determined experimentally. The short-chain alcohols, which are completely miscible with water (methanol, ethanol, 1-propanol, 2propanol, and tert-butanol) and most of the common salts (those with $\mathrm{Na}^{+}$, $\mathrm{K}^{+}, \mathrm{Ca}^{2+}$, and $\mathrm{NH}_{4}{ }^{+}$cations and $\mathrm{Cl}^{-}, \mathrm{SO}_{4}{ }^{2-}, \mathrm{CO}_{3}{ }^{2-}$, and $\mathrm{NO}_{3}{ }^{-}$anions), were studied. Experimentally determined data increased future development opportunities of column sequences and process design using aqueous twophase systems (ATPSs) by establishing alcohols, some salts, and their

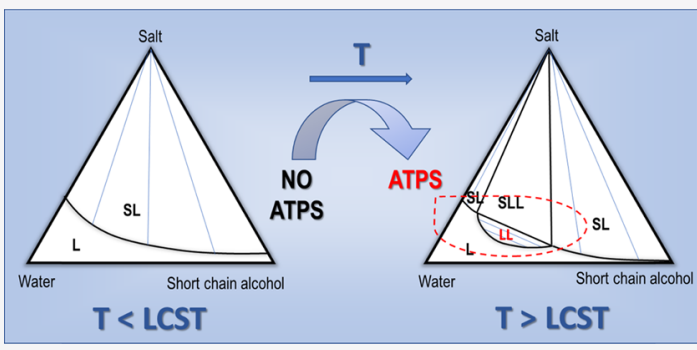
operational limits. An example using these systems in phase transition extraction (PTE) separation processes was proposed and discussed. Finally, the use of different thermodynamic models, such as the extended UNIQUAC for electrolytes and the electrolyte nonrandom two-liquid (NRTL) model, for equilibrium calculations and the LCSTs necessary for simulation of these extraction processes with ATPS systems were analyzed.

\section{INTRODUCTION}

Aqueous two-phase systems (ATPSs) are a type of water + electrolyte + solvent system that can be used for separation and purification of compounds, opening a new field of research. These systems contain regions where the mixtures split into two liquid phases in equilibrium, and both phases contain a high percentage of water, generally more than $50 \%$. They can be obtained by mixing aqueous solutions with a miscible or partially miscible compound and a splitting agent that produces partial miscibility above certain critical conditions, such as temperature or concentration. Since water is the solvent in both phases, ATPS can provide adequate and nondestructive conditions for the separation and recovery of labile biomolecules (proteins, enzymes, DNA, or RNA) and also of biological particles (cells, bacteria, or viruses). ${ }^{1}$

Traditionally, solvents used in this type of system are mixtures of two polymers or a polymer and a salt. However, salt + shortchain alcohol ATPSs are considered a promising alternative because they are much cheaper than polymers and copolymers blends ${ }^{1}$ and they can easily prevent other disadvantages, such as high viscosity, difficult separations, and tendencies to form emulsions.

Short-chain alcohols-methanol, ethanol, 1-propanol, 2propanol, and 2-methyl-2-propanol (tert-butanol)-are completely miscible in water at any temperature. However, the presence of certain salts in sufficient quantities can cause splitting of the mixture into two liquid phases, ${ }^{2}$ both containing a high concentration of water, leading to an ATPS capable of carrying out the aforementioned separations.

Two different possible shapes of the equilibrium diagrams for a system of water + nonhydrate forming salt + short-chain alcohol at a constant temperature are represented in Figure 1. In the type (a) diagram, there is only one liquid region and a solidliquid (SL) region, but in the type (b) diagram, there is a liquidliquid (LL) region and a large solid-liquid-liquid (SLL) region, characteristic of ATPS. For the existence of these regions with two liquids, the water + alcohol + salt mixture compositions must be within a very specific range. Further, the mixture must contain a minimum salt concentration for phase splitting, and moreover, the water/alcohol proportion must be between certain values. In fact, water + alcohol mixtures rich in alcohol are unable to split. Temperature is also critical in these processes. There are systems where no liquid phase splitting occurs below a given temperature, independent of the mixture composition, with type (a) equilibrium diagrams. Above this specific temperature-the low critical solution temperature (LCST), also called the lower consolute temperature ${ }^{3}$ - there are mixture compositions that produce LL phase splitting, and

Received: November 30, 2020

Revised: January 11, 2021

Accepted: January 22, 2021

Published: February 3, 2021

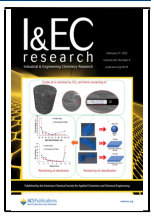



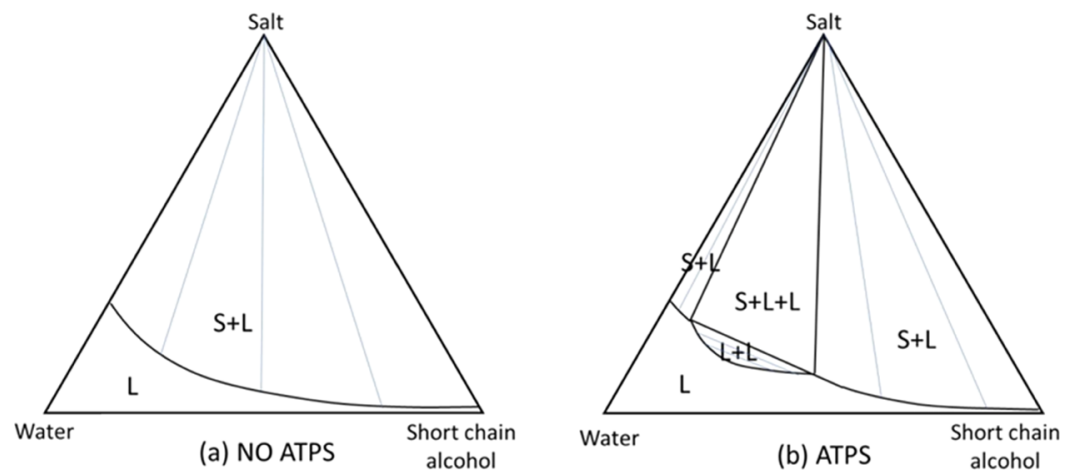

Figure 1. Equilibrium diagrams for systems (a) without and (b) with ATPS containing water, a nonhydrate forming salt, and a short-chain alcohol at a constant temperature.

Table 1. Suppliers and Mass Fraction Purities of Compounds Used

\begin{tabular}{|c|c|c|c|c|}
\hline chemical & CAS registry no. & provider & purity $^{a}$ (mass fraction) & water content $\mathrm{KF}^{b}$ (mass fraction) \\
\hline methanol & $67-56-1$ & Merck & $>0.998$ & 0.0006 \\
\hline ethanol & $64-17-5$ & VWR & $>0.998$ & 0.0002 \\
\hline 1-propanol & $71-23-8$ & Merck & $>0.995$ & 0.0006 \\
\hline 2-propanol & $67-63-0$ & Merck & $>0.995$ & 0.0009 \\
\hline 2-methyl-2-propanol (tert-butanol) & $75-65-0$ & VWR & $>0.999$ & 0.0002 \\
\hline$\left(\mathrm{NH}_{4}\right)_{2} \mathrm{CO}_{3}$ & $10361-29-2$ & Panreac & $\left(\right.$ as $\left.\mathrm{NH}_{3}\right)>0.300$ & \\
\hline $\mathrm{NH}_{4} \mathrm{Cl}$ & $12125-02-9$ & Acros Organics & 0.996 & \\
\hline $\mathrm{NH}_{4} \mathrm{NO}_{3}$ & $6484-52-2$ & Panreac & 0.980 & \\
\hline$\left(\mathrm{NH}_{4}\right)_{2} \mathrm{SO}_{4}$ & $7783-20-2$ & Acros Organics & $>0.990$ & \\
\hline $\mathrm{CaCO}_{3}$ & $471-34-3$ & Fisher Scientific & $>0.990$ & \\
\hline $\mathrm{CaCl}_{2}$ & $10043-52-4$ & Merck & $>0.980$ & \\
\hline $\mathrm{Ca}\left(\mathrm{NO}_{3}\right)_{2} \cdot 4 \mathrm{H}_{2} \mathrm{O}$ & $13477-34-4$ & Panreac & $0.990-1.03$ & \\
\hline $\mathrm{CaSO}_{4} \cdot 2 \mathrm{H}_{2} \mathrm{O}$ & $10101-41-4$ & Merck & $0.990-1.02$ & \\
\hline $\mathrm{Na}_{2} \mathrm{CO}_{3}$ & $497-19-8$ & Panreac & $>0.995$ & \\
\hline $\mathrm{NaCl}$ & $7647-14-5$ & VWR & $>0.999$ & \\
\hline $\mathrm{NaNO}_{3}$ & $7631-99-4$ & VWR & $>0.999$ & \\
\hline $\mathrm{Na}_{2} \mathrm{SO}_{4}$ & $7757-82-6$ & Panreac & 0.990 & \\
\hline $\mathrm{K}_{2} \mathrm{CO}_{3}$ & $584-08-7$ & Merck & $>0.999$ & \\
\hline $\mathrm{KCl}$ & $7447-40-7$ & VWR & $>0.999$ & \\
\hline $\mathrm{KNO}_{3}$ & $7757-79-1$ & Panreac & 0.990 & \\
\hline $\mathrm{K}_{2} \mathrm{SO}_{4}$ & $7778-80-5$ & Acros Organics & $>0.990$ & \\
\hline
\end{tabular}

their equilibrium diagrams become type (b). The LCST is the minimum temperature at which phase splitting can occur and is specific to each system, and together with the range of composition mixtures that split into two liquid phases, they constitute the operational limits of ATPS's.

However, despite the potential of water + short-chain alcohols + salt ATPSs, the type and amount of salt and alcohol and the temperature that can cause phases to split are difficult to find in the literature since there is little experimental data reported. ${ }^{2-7}$ The first aim of this research is to determine, experimentally, the LCSTs and minimum salt concentrations required for phase splitting in water + short-chain alcohol mixtures using alcohols that are completely miscible in water (methanol, ethanol, 1propanol, 2-propanol, and 2-methyl-2-propanol (tert-butanol)) and some of the most common salts (with $\mathrm{Na}^{+}, \mathrm{K}^{+}, \mathrm{Ca}^{2+}$, and $\mathrm{NH}_{4}{ }^{+}$cations and $\mathrm{Cl}^{-}, \mathrm{SO}_{4}{ }^{2-}, \mathrm{CO}_{3}{ }^{2-}$, and $\mathrm{NO}_{3}{ }^{-}$anions), providing a reliable and useful tool by describing the operation conditions, LCST, and compositions for these mixtures.

This information improves future development of column sequences and process designs by establishing short-chain alcohols and some salts suitable for ATPS and its operational limits. The data also informs our knowledge of which systems can be used in separation processes, known as phase transition extractions (PTEs). ${ }^{8}$ The main idea of these processes is based on the use of solvents with the critical point of miscibility with the liquids being extracted. Often, the formation of emulsions and slow coalescence due to the presence of cells yield finely divided solids and impurities during LL extraction processes; for example, fermentation broth causes the formation of stable dispersions with most solvents. However, by manipulating the solvent temperatures with an LCST across the coexistence curve, one can alternately create regions where solvents either form homogeneous liquid solutions or separate into two liquid phases. Hence, the mixing and settling sections with conventional extraction equipment are replaced in PTE by heated and cooled sections. The formation of a single liquid phase in the mixing section results in substantially superior contact between the solvents, eliminating the need for intense agitation. Coalescence upon temperature changes, the formation of two liquid phases, and the consequent settling stage are rapid, since the continuous changes in composition prevent the formation of stable interfaces on which solids or emulsions forming 
impurities can adhere. In a second part of this work, an example of this type of separation process using ATPS is proposed and discussed.

Finally, the simulation of processes using these types of systems requires disposing the model used to calculate equilibrium and, especially, the system LCST in the case of PTEs. In the third part of this work, problems related to the use of different thermodynamic models to calculate the equilibrium in these ATPSs are analyzed.

\section{EXPERIMENTAL SECTION}

2.1. Materials. The chemicals employed in this work, their purity, and their provenance are summarized in Table 1. Compounds were used as provided, without further purification. The water, with a conductivity no higher than $2 \mu \mathrm{S} / \mathrm{cm}$ measured with a Crison GLP 32, was deionized with two reverse-osmosis steps and an ionic-exchange resin step using a Millipore Milli-Q plus system. The hydrated salts, $\mathrm{Ca}\left(\mathrm{NO}_{3}\right)_{2}$. $4 \mathrm{H}_{2} \mathrm{O}$ and $\mathrm{CaSO}_{4} \cdot 2 \mathrm{H}_{2} \mathrm{O}$, were heated at $200{ }^{\circ} \mathrm{C}$ at atmospheric pressure to obtain the anhydrous salt.

2.2. Methods. 2.2.1. LCST Determination. Experiments were conducted in $10 \mathrm{~mL}$ tubes placed in a transparent thermostatic bath, as shown in Figure 2. The bath was thermally

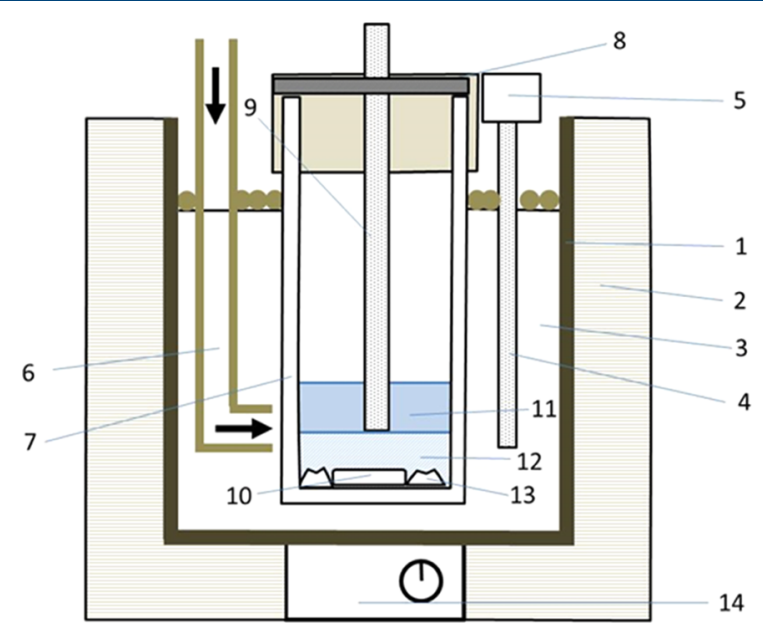

Figure 2. Equipment used for LCST determination: (1) transparent bath, (2) insulation, (3) ethylene glycol aqueous solution, (4) bath temperature probe, (5) temperature controller, (6) solution from thermostat, (7) glass flat-bottom tube, (8) screw cap with septum, (9) temperature probe, (10) stir bar, (11) upper phase, (12) lower phase, (13) excess salt, and (14) magnetic stirrer.

isolated to reduce heat loss and filled with a mixture of ethylene glycol and water to extend the experimental range of working temperatures. A magnetic stirrer was placed below the bath to permit continuous agitation of the mixture. A temperature probe, model CKT 100 from Anton Paar with an uncertainty of $0.01{ }^{\circ} \mathrm{C}$, was submerged inside the mixture to read the temperature(s) inside the liquid phase(s).

For each system, different mixtures of water, alcohol, and salt were weighed and placed in transparent tubes with a stir bar. First, the best mixture for LCST determination was selected according to the following conditions. At a temperature slightly above the estimated LCST, the sample should be in the SLL region of the system and very close to the plait point of the binodal curve. Therefore, it should split into two liquid phases with the same volume for each liquid layer. Moreover, the amount of undissolved salt should be small to facilitate visualization of the two liquid phases. Finally, the total amount of sample in the tube should be enough to identify the presence of an interphase, without being large enough, to minimize the temperature gradients that occur along the tube.

For each system, the tube with the chosen mixture and stir bar was placed in the thermostatic bath at a constant temperature, where stirring of the phases was maintained for at least an hour. Then, the mixture was left to decant, to observe by visual inspection whether either one or two liquid phases with undissolved salt were present. Subsequently, the temperature inside the tube was registered and increased if there was only one liquid phase or decreased if two liquid phases were present. The process was repeated, step-by-step, with smaller temperature increases or decreases until the LCST was obtained.

Special care was taken to avoid errors in LCST determination due to supersaturation of the solution. Moreover, in systems with possible hydrated salts, the degree of hydration of the undissolved salt corresponding to the equilibrium was verified, since the transition in the solid phase of the salt structure from a given degree of hydration to others must be a slow process. For all of these systems, tubes with water + alcohol + salt mixture were placed at higher temperatures than the LCST to dissolve all of the salt. Subsequently, the temperature of the bath was fixed at approximately $1{ }^{\circ} \mathrm{C}$ lower than the estimated LCST until the salt precipitated with the hydration degree corresponding to the equilibrium with the liquid phase at that temperature. Then, the bath temperature was increased, step-by-step, with low increments of temperature (around $0.1^{\circ} \mathrm{C}$ ) until reaching the LCST. The process of increasing and decreasing the temperature below and above the LCST was repeated several times to ensure that the determined temperature was truly the LCST.

For some systems, visually verifying the existence of one or two liquid phases was highly challenging because the difference in the refractive index between the two liquid phases was small. To prevent some error due to this fact, samples from the top and bottom of the tube were taken and analyzed by gas chromatography using the conditions described in the next section. If the area ratios of each component in each sample differed significantly, phase splitting had taken place, and the LCST was surpassed.

The studied LCST ranged between -10 and $80^{\circ} \mathrm{C}$. To extend this range of LCST values to higher temperatures, the tubes with solid and liquid phases with LCSTs higher than $80{ }^{\circ} \mathrm{C}$ were hermetically closed and introduced to an oven at $120^{\circ} \mathrm{C}$. No phase splitting was observed in any of the samples.

During all of the experiments, the temperature of the sample was monitored and controlled. Agitation of both the bath and sample mixture was continuous; temperature could be set to within $0.05{ }^{\circ} \mathrm{C}$. However, considering the very small temperature gradient in the sample, the difficulty observing the presence of one or two liquid phases and volume control of the two liquid phases was the same; an overall LCST uncertainty is likely around $\pm 0.1^{\circ} \mathrm{C}$.

2.2.2. Compositions of the Two Liquid Phases in the Vicinity of the LCST. To determine the operational limits of each system, in addition to the LCST, we must know the compositions of the water and alcohol systems that can split into two liquid phases, as well as the necessary salt concentrations. For this reason, the composition of an LL tie line, corresponding to the SLL region in the vicinity of the critical point, was determined. This was achieved using the methodology previously developed. ${ }^{9}$ Samples of global composition equal to those used for LCST determination 
were placed in a thermostatic bath at a temperature $1{ }^{\circ} \mathrm{C}$ higher than the LCST. The samples were stirred intensively for at least $2 \mathrm{~h}$ and left to settle for $24 \mathrm{~h}$, to ensure that equilibrium was reached. Then, the upper and lower liquid phases were separated by syringes, previously heated to the LCST to avoid salt precipitation during sampling. From the aliquots, salt content was determined gravimetrically at $200^{\circ} \mathrm{C}$, with the exception of $\mathrm{CaCl}_{2}$, which was determined at $350{ }^{\circ} \mathrm{C}$.

Other aliquots of each phase were taken and injected directly into the chromatograph to quantify alcohol and water contents. Glass wool was placed in the liners of the injection system to avoid salt precipitation by solvent evaporation upon injection into the chromatography column. The analysis was completed with a Shimadzu GC14B chromatograph and a conductivity detector with an 80/100 Porapak Q packed column $(2 \mathrm{~m} \times 3$ $\mathrm{mm})$. The temperatures were as follows: oven $=190{ }^{\circ} \mathrm{C}$; conductivity detector $=210^{\circ} \mathrm{C}$; and injector $=210^{\circ} \mathrm{C}$. Helium was used as the carrier gas with a flow rate of $45 \mathrm{~mL} / \mathrm{min}$. For the quantitative analysis of the samples, the standard calibration method was used. The concentrations of water and alcohol in the unknown samples were determined by comparison with standards of a known concentration.

The relative standard uncertainty of component concentrations during analysis, expected from the combination of temperature, sampling, weighing, and analytical variations, was 0.02 , except for the salt in the organic phase, where the relative standard uncertainty was 0.05 .

\section{RESULTS AND DISCUSSION}

3.1. Experimental Results. The results obtained for each short-chain alcohol are presented in Tables 2-6. Each salt is

\section{Table 2. LCST for Water + Methanol + Salt Systems}

\begin{tabular}{cclll}
\multicolumn{1}{c}{$\mathrm{M}$} & \multicolumn{1}{c}{$\mathrm{Na}^{+}$} & \multicolumn{1}{c}{$\mathrm{K}^{+}$} & \multicolumn{1}{c}{$\mathrm{NH}_{4}^{+}$} & $\mathrm{Ca}^{2+}$ \\
$\mathrm{Cl}^{-}$ & no ATPS & no ATPS & no ATPS & no ATPS \\
$\mathrm{NO}_{3}{ }^{-}$ & no ATPS & no ATPS & no ATPS & no ATPS \\
$\mathrm{SO}_{4}{ }^{2-}$ & no ATPS & no ATPS & no ATPS & no ATPS \\
$\mathrm{CO}_{3}{ }^{2-}$ & no ATPS & ATPS & no ATPS & \\
& & no ATPS
\end{tabular}

${ }^{a}$ Ammonium carbonate decomposes as it is heated.

Table 3. LCST for Water + Ethanol + Salt Systems

\begin{tabular}{cclll}
\multicolumn{1}{c}{$\mathrm{E}$} & \multicolumn{1}{c}{$\mathrm{Na}^{+}$} & \multicolumn{1}{c}{$\mathrm{K}^{+}$} & \multicolumn{1}{c}{$\mathrm{NH}_{4}^{+}$} & $\mathrm{Ca}^{2+}$ \\
$\mathrm{Cl}^{-}$ & no ATPS & no ATPS & no ATPS & no ATPS \\
$\mathrm{NO}_{3}{ }^{-}$ & no ATPS & no ATPS & no ATPS & no ATPS \\
$\mathrm{SO}_{4}{ }^{2-}$ & no ATPS & no ATPS & $10.07^{\circ} \mathrm{C}$ & no ATPS \\
$\mathrm{CO}_{3}{ }^{2-}$ & $27.58{ }^{\circ} \mathrm{C}$ & ATPS & no ATPS & \\
& & no ATPS
\end{tabular}

${ }^{a}$ Ammonium carbonate decomposes as it is heated.

represented in a cell combination with cations shown in each column and anions in rows. Then, each cell indicates either (1) no ATPS (the salt is not able to split the water and alcohol mixture into two liquid phases at temperatures lower than 120 ${ }^{\circ} \mathrm{C}$ ) or (2) ATPS (the salt is able to split the water and alcohol mixture at any temperature higher than -10 or $0{ }^{\circ} \mathrm{C}$ in the case of tert-butanol). Additionally, the LCST is noted when in the range between -10 and $120^{\circ} \mathrm{C}$ (or $0-120^{\circ} \mathrm{C}$ for tert-butanol). LCST values for systems with tert-butanol cannot be determined below $0{ }^{\circ} \mathrm{C}$ since the organic phases freeze at lower temperatures. Similarly, LCSTs for ammonium carbonate cannot be determined for most systems since the salt decomposes with an increase in temperature. Tables 2-6 also
Table 4. LCST for Water + 2-Propanol + Salt Systems

\begin{tabular}{ccccc}
$2-\mathrm{P}$ & $\mathrm{Na}^{+}$ & \multicolumn{1}{c}{$\mathrm{K}^{+}$} & $\mathrm{NH}_{4}^{+}$ & $\mathrm{Ca}^{2+}$ \\
$\mathrm{Cl}^{-}$ & $-4.85{ }^{\circ} \mathrm{C}$ & $25.20^{\circ} \mathrm{C}$ & $36.88{ }^{\circ} \mathrm{C}$ & $1.71{ }^{\circ} \mathrm{C}$ \\
& & $25.3{ }^{\circ} \mathrm{C}^{9}$ & & \\
& & $24.5^{\circ} \mathrm{C}^{10}$ & & \\
$\mathrm{NO}_{3}{ }^{-}$ & $6.10^{\circ} \mathrm{C}$ & $46.97{ }^{\circ} \mathrm{C}$ & $8.13{ }^{\circ} \mathrm{C}$ & ATPS \\
$\mathrm{SO}_{4}{ }^{2-}$ & $6.1{ }^{\circ} \mathrm{C}^{7}$ & $47.2{ }^{\circ} \mathrm{C}^{5}$ & & \\
& $28.37^{\circ} \mathrm{C}$ & no ATPS & ATPS & no ATPS \\
$\mathrm{CO}_{3}{ }^{2-}$ & $28.8{ }^{\circ} \mathrm{C}^{4}$ & & & \\
& $23.53{ }^{\circ} \mathrm{C}$ & ATPS & no ATPS & no ATPS \\
& $23.8{ }^{\circ} \mathrm{C}^{3}$ & & &
\end{tabular}

${ }^{a}$ Ammonium carbonate decomposes as it is heated.

Table 5. LCST for Water + 1-Propanol + Salt Systems

\begin{tabular}{cclcc}
$1-\mathrm{P}$ & \multicolumn{1}{c}{$\mathrm{Na}^{+}$} & \multicolumn{1}{c}{$\mathrm{K}^{+}$} & \multicolumn{1}{c}{$\mathrm{NH}_{4}^{+}$} & $\mathrm{Ca}^{2+}$ \\
$\mathrm{Cl}^{-}$ & ATPS & $-2.05{ }^{\circ} \mathrm{C}$ & $0.96{ }^{\circ} \mathrm{C}$ & ATPS \\
& & $-2.0{ }^{\circ} \mathrm{C}^{11}$ & & \\
$\mathrm{NO}_{3}{ }^{-}$ & ATPS & $32.09{ }^{\circ} \mathrm{C}$ & $-7.01{ }^{\circ} \mathrm{C}$ & ATPS \\
& & $32.1^{\circ} \mathrm{C}^{6}$ & & \\
$\mathrm{SO}_{4}{ }^{2-}$ & $22.56{ }^{\circ} \mathrm{C}$ & no ATPS & ATPS & no ATPS \\
$\mathrm{CO}_{3}{ }^{2-}$ & $15.80^{\circ} \mathrm{C}$ & ATPS & no ATPS & no ATPS
\end{tabular}

${ }^{a}$ Ammonium carbonate decomposes as it is heated.

Table 6. LCST for Water + tert-Butanol + Salt Systems

\begin{tabular}{lllll}
\multicolumn{1}{c}{$\mathrm{TB}$} & \multicolumn{1}{c}{$\mathrm{Na}^{+}$} & \multicolumn{1}{c}{$\mathrm{K}^{+}$} & \multicolumn{1}{c}{$\mathrm{NH}_{4}^{+}$} & \multicolumn{1}{c}{$\mathrm{Ca}^{2+}$} \\
$\mathrm{Cl}^{-}$ & ATPS & $0.75{ }^{\circ} \mathrm{C}$ & ATPS & ATPS \\
$\mathrm{NO}_{3}{ }^{-}$ & ATPS & $28.60{ }^{\circ} \mathrm{C}$ & ATPS & ATPS \\
$\mathrm{SO}_{4}{ }^{2-}$ & $22.71{ }^{\circ} \mathrm{C}$ & $45.25{ }^{\circ} \mathrm{C}$ & ATPS & no ATPS \\
& $22.8{ }^{\circ} \mathrm{C}^{4}$ & & & \\
$\mathrm{CO}_{3}{ }^{2-}$ & $17.56{ }^{\circ} \mathrm{C}$ & ATPS & $16.97{ }^{\circ} \mathrm{C}$ & no ATPS \\
& $17.8{ }^{\circ} \mathrm{C}^{3}$ & & & \\
\hline
\end{tabular}

include the bibliographic LCST values, if available. Overall, the differences between previously determined values and our values were very small.

The ratio of water/alcohol (mole fraction), which can form ATPS, was between $9 / 1$ and $1 / 1$. For ratios higher or lower than $9 / 1$ or $1 / 1$, respectively, the salt was unable to split the water and alcohol mixtures into two liquid phases. The concentration of salt needed to split the mixture into two liquid phases was between 50 and $90 \%$ of the solubility of salt in pure water.

By comparing different alcohols with the same salts and analyzing the LCST of each one, we can clearly deduce the ability of each system to form ATPS, which decreases as follows: tert-butanol $>$ 1-propanol $>2$-propanol $>$ ethanol $>$ methanol.

Of the 16 investigated salts, only potassium carbonate was able to split the water + methanol mixture into two phases, while most of the other salts split water + tert-butanol solutions. Water + ethanol mixtures only can be split with three examined salts and two of them with an LCST. Sodium sulfate has been referenced ${ }^{12}$ as being capable of splitting aqueous solutions of ethanol. However, another more recent work ${ }^{13}$ showed the equilibrium diagram of the system with a unique SL solubility curve, where the salt is unable to split the liquid mixture into two phases. We have not found any global mixture or conditions that obtain two liquid phases for this alcohol, even when preparing samples described in previous references.

With respect to the ability of individual constituent salt ions to form ATPS, there is no defined tendency. The solution's saltingout ability, from the point of view of the minimum LCST, does 
Table 7. Ability of Different Salts to Split Aqueous Solutions of the Five Short-Chain Alcohols, Which Are Completely Miscible in Water (M, Methanol; E, Ethanol; 2-P, 2-Propanol; 1-P, 1-Propanol; and TB, tert-Butanol), into Two Liquid Phases ${ }^{a}$

\begin{tabular}{|c|c|c|c|c|c|c|c|c|c|}
\hline & \multirow{2}{*}{$\frac{M}{\exp }$} & \multirow{2}{*}{$\frac{E}{\exp }$} & \multicolumn{2}{|c|}{ 2-P } & \multicolumn{2}{|c|}{$1-P$} & \multirow{2}{*}{$\frac{\mathrm{TB}}{\exp }$} & \multirow{2}{*}{$\frac{\mathrm{S}^{15} \text { of salt in water at } 20^{\circ} \mathrm{C}}{\text { mole fraction }}$} & \multirow[b]{2}{*}{$I_{x}$} \\
\hline & & & $\exp$ & $\mathrm{cal}$ & $\exp$ & $\mathrm{cal}$ & & & \\
\hline potassium carbonate & ATPS & ATPS & ATPS & ATPS & ATPS & 39.7 & ATPS & 0.125 & 0.300 \\
\hline ammonium sulfate & $\mathrm{N}$ & 10.07 & ATPS & ATPS & ATPS & ATPS & ATPS & 0.093 & 0.235 \\
\hline sodium carbonate & $\mathrm{N}$ & 27.58 & 23.53 & 36.9 & 15.80 & 24.8 & 17.56 & 0.036 & 0.101 \\
\hline calcium nitrate & $\mathrm{N}$ & $\mathrm{N}$ & ATPS & & ATPS & & ATPS & 0.126 & 0.302 \\
\hline sodium chloride & $\mathrm{N}$ & $\mathrm{N}$ & -4.85 & -6.2 & ATPS & ATPS & ATPS & 0.100 & 0.091 \\
\hline calcium chloride & $\mathrm{N}$ & $\mathrm{N}$ & 1.71 & & ATPS & & ATPS & 0.106 & 0.262 \\
\hline sodium nitrate & $\mathrm{N}$ & $\mathrm{N}$ & 6.1 & & ATPS & & ATPS & 0.156 & 0.135 \\
\hline ammonium nitrate & $\mathrm{N}$ & $\mathrm{N}$ & 8.13 & 9.6 & -7.01 & & ATPS & 0.299 & 0.230 \\
\hline potassium chloride & $\mathrm{N}$ & $\mathrm{N}$ & 25.20 & -0.3 & -2.05 & -11.1 & 0.75 & 0.076 & 0.071 \\
\hline ammonium chloride & $\mathrm{N}$ & $\mathrm{N}$ & 36.88 & -4.9 & 0.96 & ATPS & ATPS & 0.112 & 0.101 \\
\hline sodium sulfate & $\mathrm{N}$ & $\mathrm{N}$ & 28.37 & 32.2 & 22.56 & 32.3 & 22.71 & 0.0234 & 0.067 \\
\hline potassium nitrate & $\mathrm{N}$ & $\mathrm{N}$ & 46.97 & 39.6 & 32.09 & & 28.6 & 0.054 & 0.051 \\
\hline ammonium carbonate & $\mathrm{N}^{b}$ & $\mathrm{~N}^{b}$ & $\mathrm{~N}^{b}$ & & $\mathrm{~N}^{b}$ & $\mathrm{~N}$ & 16.97 & 0.044 & 0.121 \\
\hline potassium sulfate & $\mathrm{N}$ & $\mathrm{N}$ & $\mathrm{N}$ & $\mathrm{N}$ & $\mathrm{N}$ & $\mathrm{N}$ & 45.25 & 0.011 & 0.032 \\
\hline calcium sulfate & $\mathrm{N}$ & $\mathrm{N}$ & $\mathrm{N}$ & & $\mathrm{N}$ & & $\mathrm{N}$ & $<0.001$ & $<0.008$ \\
\hline calcium carbonate & $\mathrm{N}$ & $\mathrm{N}$ & $\mathrm{N}$ & & $\mathrm{N}$ & & $\mathrm{N}$ & $<0.001$ & $<0.008$ \\
\hline
\end{tabular}

${ }^{a}$ Exp, experimental; Cal, calculated with extended UNIQUAC. If the salt is able to split the water + alcohol mixture, the LCST ( $\left.{ }^{\circ} \mathrm{C}\right)$ or "ATPS" (if LCST $<-10{ }^{\circ} \mathrm{C}$ or $<0{ }^{\circ} \mathrm{C}$ for TB) is given. "N" indicates no capacity. "S" is the solubility of the salt in water at $20{ }^{\circ} \mathrm{C}$ (mole fraction) and $I_{x}$ is the ionic strength (mole fraction basis) of the aqueous saturated solution at that temperature. ${ }^{b}$ Ammonium carbonate decomposes as it is heated.

Table 8. Solid-Liquid-Liquid Equilibrium Data (Mole Fraction) of the Different Water + Alcohol + Salt at Temperature $1{ }^{\circ} \mathrm{C}$ Higher Than the $\operatorname{LCST}^{a}$

\begin{tabular}{|c|c|c|c|c|c|c|c|}
\hline & \multirow[b]{2}{*}{$T\left({ }^{\circ} \mathrm{C}\right)$} & \multicolumn{3}{|c|}{ aqueous phase } & \multicolumn{3}{|c|}{ organic phase } \\
\hline & & water & alcohol & salt & water & alcohol & salt \\
\hline \multicolumn{8}{|l|}{ alcohol: ethanol } \\
\hline ammonium sulfate & 11.1 & 0.892 & 0.0516 & 0.0567 & 0.814 & 0.170 & 0.0161 \\
\hline sodium carbonate & 28.8 & 0.934 & 0.0176 & 0.0485 & 0.871 & 0.121 & 0.00825 \\
\hline \multicolumn{8}{|l|}{ alcohol: 2-propanol } \\
\hline sodium carbonate & 24.6 & 0.950 & 0.0129 & 0.0375 & 0.785 & 0.212 & 0.00238 \\
\hline sodium chloride & -3.7 & 0.845 & 0.0794 & 0.0752 & 0.579 & 0.398 & 0.0223 \\
\hline calcium chloride & 2.6 & 0.826 & 0.0827 & 0.0912 & 0.624 & 0.298 & 0.0783 \\
\hline sodium nitrate & 7.3 & 0.840 & 0.0552 & 0.105 & 0.666 & 0.296 & 0.0382 \\
\hline ammonium nitrate & 9.2 & 0.727 & 0.0953 & 0.178 & 0.550 & 0.346 & 0.105 \\
\hline potassium chloride & 26.1 & 0.841 & 0.108 & 0.0513 & 0.691 & 0.281 & 0.0278 \\
\hline ammonium chloride & 37.7 & 0.792 & 0.116 & 0.0920 & 0.615 & 0.313 & 0.0716 \\
\hline sodium sulfate & 29.5 & 0.946 & 0.0152 & 0.0387 & 0.788 & 0.210 & 0.00221 \\
\hline potassium nitrate & 48.0 & 0.847 & 0.0837 & 0.0689 & 0.731 & 0.235 & 0.0341 \\
\hline \multicolumn{8}{|l|}{ alcohol: 1-propanol } \\
\hline sodium carbonate & 17.0 & 0.936 & 0.0529 & 0.0113 & 0.771 & 0.226 & 0.0025 \\
\hline ammonium nitrate & -5.8 & 0.763 & 0.0913 & 0.146 & 0.604 & 0.337 & 0.0587 \\
\hline potassium chloride & -0.9 & 0.883 & 0.0760 & 0.0413 & 0.680 & 0.305 & 0.0152 \\
\hline ammonium chloride & 2.2 & 0.832 & 0.100 & 0.0681 & 0.673 & 0.284 & 0.0430 \\
\hline sodium sulfate & 23.6 & 0.873 & 0.111 & 0.0162 & 0.762 & 0.237 & 0.00171 \\
\hline potassium nitrate & 32.9 & 0.864 & 0.0889 & 0.0468 & 0.737 & 0.240 & 0.0231 \\
\hline \multicolumn{8}{|l|}{ alcohol: tert-butanol } \\
\hline sodium carbonate & 18.6 & 0.951 & 0.0319 & 0.0171 & 0.774 & 0.225 & 0.00104 \\
\hline potassium chloride & 1.6 & 0.880 & 0.0783 & 0.0416 & 0.743 & 0.246 & 0.0114 \\
\hline sodium sulfate & 23.6 & 0.952 & 0.0343 & 0.0140 & 0.775 & 0.223 & 0.00131 \\
\hline potassium nitrate & 29.5 & 0.896 & 0.0638 & 0.0400 & 0.740 & 0.242 & 0.0183 \\
\hline potassium sulfate & 46.2 & 0.926 & 0.0689 & 0.00474 & 0.826 & 0.172 & 0.00178 \\
\hline
\end{tabular}

not follow the trend of the Hofmeister series ${ }^{14}$ for anions $\left(\mathrm{CO}_{3}{ }^{2-}>\mathrm{SO}_{4}{ }^{2-}>\mathrm{Cl}^{-}>\mathrm{NO}_{3}{ }^{-}\right)$or for cations $\left(\mathrm{NH}_{4}^{+}>\mathrm{K}^{+}>\mathrm{Na}^{+}\right.$ $\left.>\mathrm{Ca}^{2+}\right)$ since there are many cases that do not fulfill it.

There is a certain relationship between the ability of salts to form ATPS and the solubility of the salt in pure water or the ionic strength of the saturated aqueous solution. Table 7 shows the LCST for each alcohol and salt, ordered with respect to the ability of salts to form ATPS. The last two columns include the salt's solubility at $20{ }^{\circ} \mathrm{C}$ (mole fraction) in pure water and the ionic strength (mole fraction basis) of the aqueous saturated 


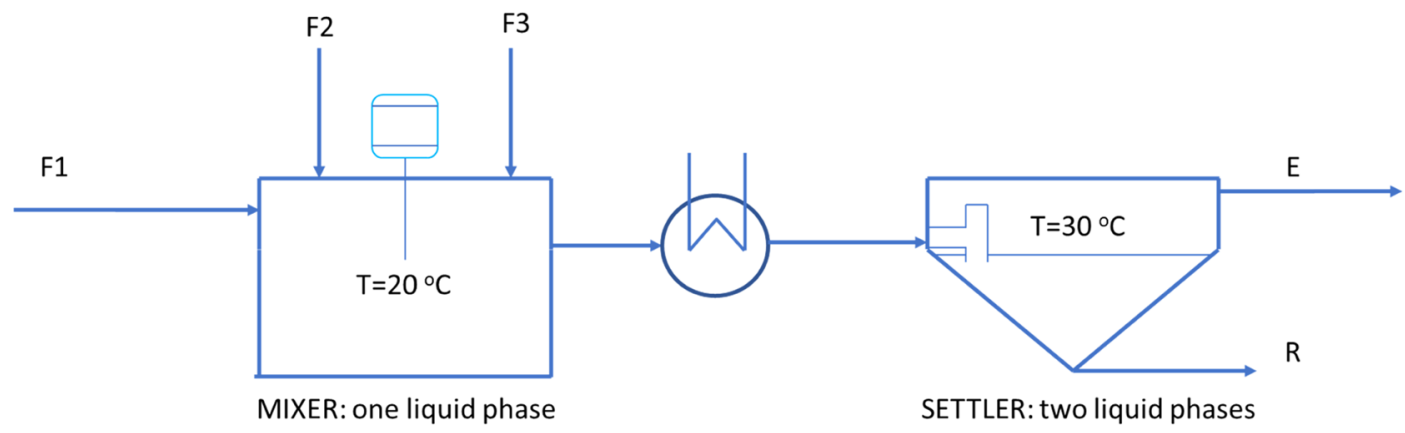

Figure 3. Flowsheet of one stage of the PTE process using ATPS.

Table 9. Flow Rate and Compositions for Streams from the Flowsheet in Figure 3

$\begin{array}{lrcccc}\text { flow rate }(\mathrm{kg} / \mathrm{h}) & \mathrm{F} 1 & \mathrm{~F} 2 & \mathrm{~F} 3 & \mathrm{E} & \mathrm{R} \\ \text { water } & 100 & & & 49.11 & 50.89 \\ \text { 2-propanol } & & 100 & & 88.61 & 11.39 \\ \text { KCl } & & & 20.59 & 5.89 & 14.70 \\ \text { A } & 0.1 & & & 0.079 & 0.021 \\ \text { total } & 100.1 & 100 & 20.59 & 143.61 & 76.98\end{array}$

Table 10. Electrolyte NRTL Interaction Parameters for the Water + KCl + 2-Propanol System $\left(\tau_{i j}=A_{i j}+B_{i j} / T ; \tau_{i j}, A_{i j}\right.$, and $\alpha_{i j}$ dimensionless; $B_{i j}$ in $\left.\mathrm{K}\right)^{a}$

$\begin{array}{lccl}\text { source } & \text { Aspen Plus databank } & \text { Aspen Plus databank } & \text { regression } \\ \text { comp 1 } & \text { water } & \text { water } & \text { 2-propanol } \\ \text { comp 2 } & \mathrm{KCl} & \text { 2-propanol } & \mathrm{KCl} \\ A_{12} & 6.93892 & 6.8284 & 22.4342 \\ A_{21} & -4.38264 & -1.3115 & 60 \\ B_{12} & 350.305 & -1483.46 & -5003.07 \\ B_{21} & -25.0926 & 426.398 & 30000 \\ \alpha_{12}=\alpha_{21} & 0.2 & 0.3 & 0.2\end{array}$

${ }^{a}$ The equation for the calculation of the solubility product of the salt is $\ln \left(K_{\text {eq }}\right)=-344.783+6881.15 / T+60.0943 \ln T-0.0959692 T(T$ in $\mathrm{K})$.

solution at that temperature. Although there is a certain relation between the ability to form ATPS and the solubility of the salt in water or the ionic strength, there are also exceptions. Obviously, the salt's solubility in the alcohol plays an important role.

Finally, the composition of the mixtures defining the SLL region of the ATPSs at temperatures $1{ }^{\circ} \mathrm{C}$ higher than the LCST was also determined since a concentration is necessary to split the mixture into two liquid phases. These critical temperatures and compositions are shown in Table 8 and can be helpful in designing separation processes (PTE) that require slight temperature changes to induce a single liquid phase or two liquid phases, one of which would contain the product to be extracted.

3.2. PTE Process with ATPS. To illustrate the use of PTE with ATPS and short-chain alcohols, we consider a process where compound $\mathrm{A}$ is dissolved in an aqueous solution containing finely divided solids and other impurities. If an LL extraction was applied, the presence of these impurities would cause the formation of stable dispersions during mixing with the solvent. To avoid them, compound A could be extracted with a short-chain alcohol that forms an ATPS at a temperature above the LCST.

As an example, 2-propanol and $\mathrm{KCl}$ were chosen for simulating a stage of the PTE process. Figure 3 shows the process flowsheet, and Table 9 contains the considered flow rates, feed compositions, and values calculated for the products. For calculations, the equilibrium data of the system with water + $\mathrm{KCl}+2$-propanol at $30{ }^{\circ} \mathrm{C}^{9}$ were used. A value of 2 was supposed for the distribution coefficient of compound $\mathrm{A}$ between the two liquid phases. The mixing section contains a cooler where the solution temperature was kept at $20^{\circ} \mathrm{C}$. At this temperature, the mixture is in the liquid region, and compound A dissolved perfectly in the miscible water +2 -propanol mixture. In the settling section, the mixture is heated at $30^{\circ} \mathrm{C}$, where two liquid phases exist, leading to a coalescence and separation of phases. The rate of both the mixing and settling processes is high since the formation of the two liquid phases in the settler is continuous throughout the entire mixture without the formation of stable interfaces on which solids or emulsion-forming impurities can adhere. With only one extraction stage, 79\% of compound A was extracted and separated from the initial broth.

This proposal of using the LCST of ATPS in an extraction process may not seem competitive with other methods that remove solid impurities by filtration prior to extraction or break stable dispersions using centrifuges. However, these processes are expensive and can also damage some of the desired products if they are degraded by shear mixing.

On the other hand, as the temperature difference between the mixer and settler is small, this PTE process is not energyintensive. Obviously, the extract has to be treated to separate compound $\mathrm{A}$ and recover the solvent, but these stages are also to be carried out in the conventional extraction process.

In the presented example, only a mixing settling stage was considered. However, with the high rates of coalescence and phase separation in the settler, several extraction stages can be applied, even in countercurrents. To design and simulate these separation operations with mixed solvent electrolyte mixtures, thermodynamic models capable of reproducing the behavior of these mixtures need to be used. They are essential for the analysis and improvement of separation processes for improved viability and energy efficiency.

3.3. Models for Calculating Equilibrium in ATPS and Problems in Data Regression of ATPS with LCST. Currently, the SLL equilibrium of the water + salt + alcohol mixtures for ATPS is clearly an extremely difficult test for any electrolyte model. The most common models for calculating the equilibrium of these systems are those of activity coefficients, such as the extended UNIQUAC model for electrolyte solutions from Thomsen et al. ${ }^{16,17}$ and the electrolyte nonrandom twoliquid (NRTL) model by Chen and Song. ${ }^{18}$ In the last few years, a new generation of models based on the equations of state have emerged with force even with electrolytes. ${ }^{19}$ Although promising advances are being made, these modeling efforts 

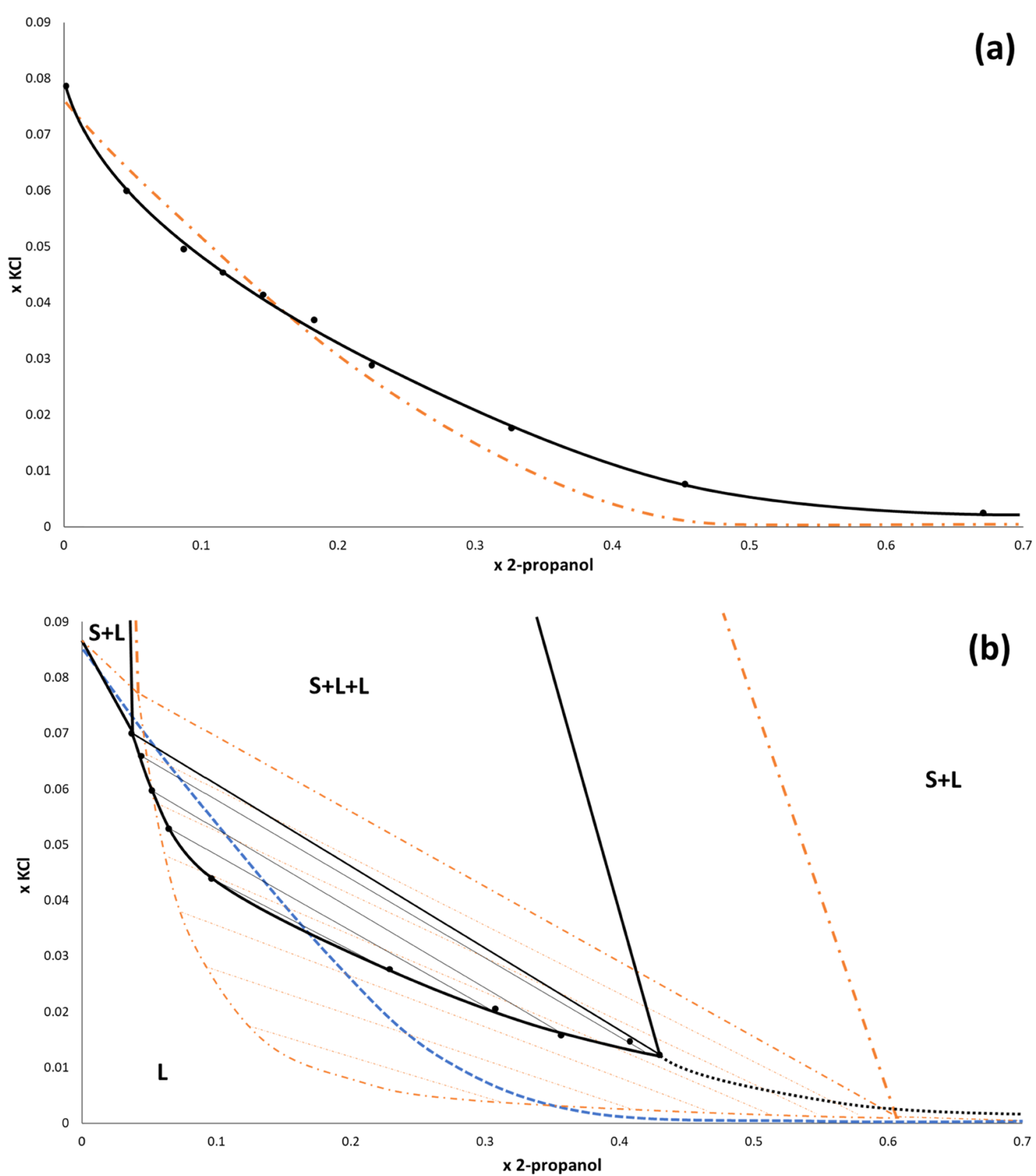

Figure 4. Phase equilibrium data of the water $+\mathrm{KCl}+2$-propanol system: (a) experimental (black line) and calculated (orange dashed-dotted line) data at $25^{\circ} \mathrm{C}$ and (b) experimental (black line) and calculated (blue dashed line) data at $40{ }^{\circ} \mathrm{C}$, together with calculated data at $45^{\circ} \mathrm{C}$ (orange dasheddotted line).

with equations of state and electrolytes are still far from reproducing equilibria between all phases of these mixtures where the influence of temperature is important.

One of the previously cited models, the extended UNIQUAC, was implemented through AQSOL software developed by the Technical University of Denmark (DTU) for calculating the number and composition of present phases, which splits a global mixture in two. The software does not directly calculate the LCST of the system, but it can be obtained by trial and error. There is only one mixture at a specific temperature and pressure, where a slight change of concentration or temperature produces a change in the number of phases present, from SL to SLL. With this method and the database of binary interaction parameters determined previously, ${ }^{20}$ valid from 0 to $100{ }^{\circ} \mathrm{C}$, the salt capacities required to split the water and alcohol mixtures were calculated. Table 7 includes the obtained results for systems with 1-propanol and 2-propanol and salts with available parameters. Results are presented in the same way as previous experimental results. LCST, ATPS, or N (no ATPS) depend on whether or not the salt is able to split water in the range of -10 to $120^{\circ} \mathrm{C}$.

The predictions of "no ATPS" or "ATPS" agree with experimental results. The calculated LCSTs show similar tendencies as experimental values with respect to the different salts, but there are important discrepancies in some temperature values.

Recognizing that the extended UNIQUAC model has merely been used as a predictive tool is important. For example, interaction parameters for 1-propanol and $\mathrm{K}^{+}$and 1-propanol and $\mathrm{CO}_{3}{ }^{2-}$, necessary for the calculation of the water $+\mathrm{K}_{2} \mathrm{CO}_{3}+$ 1-propanol system, have not been calculated from regressions of 
LL equilibrium data for that system. In contrast, they have been fitted from equilibrium data of other systems with salts containing the $\mathrm{K}^{+}$and $\mathrm{CO}_{3}{ }^{2-}$ ions, such as water $+\mathrm{Na}_{2} \mathrm{CO}_{3}+$ 1-propanol and water $+\mathrm{KCl}+1$-propanol.

Consequently, use of the extended UNIQUAC model applied to ATPS is promising; however, more experimental LL and SL equilibrium data from different systems that can be used toward obtaining new interaction parameters, especially alcohol-ion systems, is needed.

The electrolyte NRTL model, ${ }^{18}$ used by Aspentech in Aspen Plus, is another model that permits phase equilibrium calculation for ATPS. Using the original model or the reformulated symmetric activity coefficient model is possible with reference states chosen as pure liquids for solvents and pure fused salts for electrolytes. ${ }^{21}$ For both models, there are no databanks in the literature for all interaction parameters between several of the components of these systems. Therefore, it is needed to obtain these interaction parameters by regression of the equilibrium data. The necessary parameters correspond to each binary pair (water + salt, water + alcohol, alcohol + salt) and the solubility product of the salt.

The electrolyte NRTL parameters of the water + salt binary pair can be found in the bibliography or fitted from an extensive database of phase equilibria from aqueous electrolyte systems. The solubility product also can be obtained in the same way.

The parameters for the water + alcohol pair can also be found in references, such as the DECHEMA or Aspen Plus databank. These parameters have been usually regressed from experimental vapor-liquid (VL) equilibrium data of each system. All of the short-chain alcohols of this paper are completely miscible in water in any proportion, and the added salt causes splitting into two liquid phases in the mixtures. However, most sets of parameters referenced for the water + tert-butanol, 1-propanol, or even 2-propanol systems calculate partial miscibility for these water + alcohol systems at temperatures from 0 to $100{ }^{\circ} \mathrm{C}$. For example, for water + 1-propanol, there are four different sets of NRTL parameters in the Aspen Plus databank that can be used with the electrolyte NRTL model. Three erroneously calculate that there are mixtures of 1-propanol and water that split into two liquid phases without adding salt. This problem was discussed by Marcilla et al. ${ }^{22}$ The fourth set (named as "lit" by the Aspen Plus Databank) is provided by DECHEMA ${ }^{23}$ from the VL equilibrium data of Kojima et al. ${ }^{24}$ at atmospheric pressure. This pair of parameters at least calculates complete miscibility at temperatures close to the boiling point; however, it also erroneously calculates an upper critical solution temperature (UCST) of $77^{\circ} \mathrm{C}$ for that binary system. That means that at temperatures lower than $77^{\circ} \mathrm{C}$ the model calculates that the water + 1-propanol mixture splits into two liquid phases without adding salt. Consequently, these parameters must not be used to regress, for example, the LL equilibrium data at $25^{\circ} \mathrm{C}$ of the water $+\mathrm{NaCl}+1$-propanol system reported by Gomis et al. ${ }^{25}$ Although Song and Chen ${ }^{21}$ did demonstrate the application of the symmetric electrolyte NRTL model with that parameter set to that system, mixtures of water and 1-propanol can split into two liquid phases without adding salt, which is unrealistic.

With water + 2-propanol, parameters predicting that the mixture without salt splits into two liquid phases are less frequent. However, there are still many sets of parameters doing so, such as DECHEMA ${ }^{23}$ from data of Kojima et al., ${ }^{24}$ implemented in the Aspen Plus Databank. These parameters calculate a binary UCST at $31{ }^{\circ} \mathrm{C}$. Therefore, the selection of binary interaction parameters for systems with water and short- chain alcohols should be done carefully, taking into account model parameters that must not calculate splitting of phases when salt is not present.

Finally, the pair of interaction parameters corresponding to alcohol and salt has to be fitted by a regression of the experimental equilibrium data of the system. In the case of ATPSs with a ternary LCST, we must dispose of SL equilibrium data at temperatures lower than the LCST and LL and SLL equilibrium data at higher temperatures. Obviously, the unique datum of the LCST is not enough to fit the interaction parameters of that pair, which would contain at least four parameters if they are considered dependent on temperature.

Since there are not many equilibrium data of these ATPS systems with LCST, the problem of data regression for parameters of that pair will be explained with an example using the equilibrium data for the water $+\mathrm{KCl}+2$-propanol system, ${ }^{9,25}$ which has an LCST of $25.2^{\circ} \mathrm{C}$ and was used in the PTE process described above. The electrolyte NRTL with the symmetric activity coefficient model ${ }^{21}$ was used.

Parameters for water $+\mathrm{KCl}$ were taken from the Aspen Plus databank, and the solubility product was fitted using solubility data of $\mathrm{KCl}$ in water ${ }^{15}$ at different temperatures. Parameters for water and 2-propanol were taken of the Aspen Plus databank, verifying that they reproduce the VL equilibrium of the binary system and do not calculate splitting of liquid phases in this binary system in the range from 0 to $100{ }^{\circ} \mathrm{C}$. Parameters for the 2-propanol $+\mathrm{KCl}$ pair were regressed using the SL equilibrium data at 15 and $25{ }^{\circ} \mathrm{C}$ and the SLL and LL equilibrium data at $25.4,25.6,26,28,30$, and $40^{\circ} \mathrm{C} .{ }^{9,25}$ The equilibrium diagram of data at 15 and $25^{\circ} \mathrm{C}$ is similar to that in Figure 1a, and for the rest of the temperatures, it is similar to that in Figure $1 \mathrm{~b}$.

Notably, finding a pair of parameters for alcohol + salt that predicts an LCST for the system is possible, meaning that the model and their interaction parameters calculate an equilibrium diagram like in Figure $1 \mathrm{~b}$ (with an LL region) at temperatures higher than the LCST and like in Figure 1a (without an LL region) at lower temperatures. The main problem found during the regression is that reproducing an LCST as low as $25.2{ }^{\circ} \mathrm{C}$ is not possible. No values for the interaction parameters of the 2 propanol $+\mathrm{KCl}$ pair calculate the existence of SLL and $\mathrm{LL}$ regions at temperatures between 25.2 and $42{ }^{\circ} \mathrm{C}$ when the water $+\mathrm{KCl}$ and water +2 -propanol parameters were set.

Moreover, the regression and comparison between experimental and calculated equilibria to determine the objective function in data regression are not simple. On the one hand, calculations are being carried out in the vicinity of critical points for both concentration and temperature. Consequently, the activities of the different compounds in the mixtures of that region are very similar. On the other hand, for a specific temperature, we have to compare experimental data belonging to an LL region of the equilibrium diagram (Figure $1 \mathrm{~b}$ type) with calculated data with or without this LL region (Figure la type). As a consequence of all of these facts, the regression does not converge easily. To solve this problem, several sets of experimental data were eliminated from the regression and only experimental equilibrium data at 25 and $40{ }^{\circ} \mathrm{C}$ were considered. Table 10 shows the interaction parameters obtained when this regression was completed, and Figure 4 compares the experimental and calculated data.

At $25{ }^{\circ} \mathrm{C}$, the fitting is good, but at $40{ }^{\circ} \mathrm{C}$, the observed differences are important. The calculated LCST is $42^{\circ} \mathrm{C}$, and for this reason, Figure $4 \mathrm{~b}$ includes the calculated equilibrium diagram at $45^{\circ} \mathrm{C}$ (with the LL region) and at $40^{\circ} \mathrm{C}$ (without the 
$\mathrm{LL}$ region) compared with experimental data at $40{ }^{\circ} \mathrm{C}$ (with the $\mathrm{LL}$ region).

To fit better the system's LCST, different regressions were carried out, changing the water +2 -propanol parameters that had been set previously. However, the only way to decrease the LCST of the system required unrealistic water + 2-propanol parameters, indicating splitting of the mixture into two liquid phases without salt.

Different regressions were carried out with other systems, and the obtained results were similar to the system with 2-propanol and $\mathrm{KCl}$. In conclusion, the model is able to simulate ATPSs with LCST, but the differences between experimental and calculated LCST values are significant. Therefore, applying the model and parameters to the simulation of PTE is difficult, especially where the LCST value is important.

\section{CONCLUSIONS}

The LCSTs of ternary systems constituted by water, short-chain alcohols that are completely miscible with water (methanol, ethanol, 1-propanol, 2-propanol, and tert-butanol), and the most common salts (those with $\mathrm{Na}^{+}, \mathrm{K}^{+}, \mathrm{Ca}^{2+}, \mathrm{NH}_{4}^{+}$cations and $\mathrm{Cl}^{-}$, $\mathrm{SO}_{4}{ }^{2-}, \mathrm{CO}_{3}{ }^{2-}, \mathrm{NO}_{3}{ }^{-}$anions) were determined. Moreover, a tie line close to the plait point of each system at that LCST was obtained, since these mixture compositions, which split into two liquid phases, constitute the operational limits of the systems to be used for ATPS.

By comparing different alcohols with the same salts and analyzing the LCST of each one, we clearly deduced that the ability to form ATPS varies, as follows: tert-butanol > 1-propanol $>2$-propanol $>$ ethanol $>$ methanol. The ratio of water-toalcohol (mole fraction) that can form ATPS is between $9 / 1$ and $1 / 1$. For ratios higher than $9 / 1$ or lower than $1 / 1$, the salt is unable to split the water + alcohol mixtures into two liquid phases. The concentration of salt needed to split the alcohol + water mixture into two liquid phases is $50-90 \%$ of the salt solubility in pure water.

The use of these systems in separation processes for PTE was proposed and discussed with a specific example. The PTE process uses a mixer and settler at two different temperatures. As the difference in temperature between the two can be small, this PTE process is not energy-intensive. The rates of both mixing and settling are high since the formation of the two liquid phases in the settler is continuous in all of the mixtures without the formation of stable interfaces on which solids or emulsionforming impurities can adhere. With only one extraction stage, a high percentage of compound can be extracted and separated from the initial mixture.

Finally, with respect to the use of different thermodynamic models, such as the extended UNIQUAC model for electrolytes and the electrolyte NRTL model, in the calculation of the equilibrium and LCSTs, which are necessary for the simulation of extraction processes with these ATPS's, we concluded that more experimental LL and SL equilibrium data with different systems, which can be used toward obtaining new interaction parameters, especially alcohol + ion ratios, is needed. Moreover, fitting these experimental data to find interaction parameters and precisely calculating the LCST is difficult, making the application of models and parameters important in the simulation of the PTE process.

\section{AUTHOR INFORMATION}

\section{Corresponding Author}

Vicente Gomis - Chemical Engineering Department, Instituto de Ingeniería de los Procesos Químicos, University of Alicante, E-03080 Alicante, Spain; (1) orcid.org/0000-0002-0085-

8336; Email:vgomis@ua.es

\section{Authors}

Alejandro Gomis - Chemical Engineering Department, Instituto de Ingeniería de los Procesos Químicos, University of Alicante, E-03080 Alicante, Spain; 이이.org/0000-00034638-7311

Jorge García-Cano - Chemical Engineering Department, Instituto de Ingeniería de los Procesos Químicos, University of Alicante, E-03080 Alicante, Spain; (1) orcid.org/0000-00020313-8043

Alicia Font - Chemical Engineering Department, Instituto de Ingeniería de los Procesos Químicos, University of Alicante, E03080 Alicante, Spain; (1) orcid.org/0000-0003-2469-6391

Complete contact information is available at:

https://pubs.acs.org/10.1021/acs.iecr.0c05891

\section{Notes}

The authors declare no competing financial interest.

\section{ABBREVIATIONS}

ATPS aqueous two-phase system

LCST low critical solution temperature

UCST upper critical solution temperature

PTE phase transition extraction

SL solid-liquid

SLL solid-liquid-liquid

LL liquid-liquid

VL vapor-liquid

\section{REFERENCES}

(1) Iqbal, M.; Tao, Y.; Xie, S.; Zhu, Y.; Chen, D.; Wang, X.; Huang, L.; Peng, D.; Sattar, A.; Shabbir, M.; Hussain, H.; Ahmed, S.; Yuan, Z. Aqueous two-phase system (ATPS): an overview and advances in its applications. Biol. Proced. Online 2016, 18, No. 18.

(2) Timmermans, J. Die kritische Lösungstemperatur von ternären Gemengen. Z. Phys. Chem. 1907, 58, 129-131.

(3) Lynn, S.; Schiozer, A. L.; Jaecksch, W. L.; Cos, R.; Prausnitz, J. M. Recovery of anhydrous $\mathrm{Na}_{2} \mathrm{SO}_{4}$ from $\mathrm{SO}_{2}$-scrubbing liquor by extractive crystallization: Liquid-liquid equilibria for aqueous solutions of sodium carbonate, sulfate, and/or sulfite plus acetone, 2-propanol, or tert-butyl alcohol. Ind. Eng. Chem. Res. 1996, 35, 4236-4245.

(4) Brenner, D. K.; Anderson, E. W.; Lynn, S.; Prausnitz, J. M. Liquidliquid equilibria for saturated aqueous solutions of sodium sulfate +1 propanol, 2-propanol, or 2-methylpropan-2-ol. J. Chem. Eng. Data 1992, 37, 419-422.

(5) Sinegubova, S. I.; Il'in, K. K.; Cherkasov, D. G.; Kurskii, V. F.; Tkachenko, N. V. Salting-out of isopropyl alcohol from aqueous solutions with potassium nitrate. Russ. J. Appl. Chem. 2004, 77, 19241928.

(6) Sinegubova, S. I.; Cherkasov, D. G.; Il'in, K. K. Salting-out of npropyl alcohol with potassium nitrate from aqueous solutions. Russ. J. Appl. Chem. 2005, 78, 394-398.

(7) Cherkasov, D. G.; Il'in, K. K.; Kurskii, V. F. Topological transformation of a phase diagram for the sodium nitrate-waterisopropanol ternary system. Russ. J. Inorg. Chem. 2011, 56, 787-791.

(8) Ullmann, A.; Ludmer, Z.; Shinnar, R. Phase transition extraction using solvent mixtures with critical point of miscibility. AIChE J. 1995, $41,488-500$. 
(9) Gomis, V.; Ruiz, F.; Boluda, N.; Saquete, M. D. The influence of temperature on the liquid-liquid-solid equilibrium of the ternary system water-potassium chloride-2-propanol. Fluid Phase Equilib. 1997, 130, 223-229.

(10) Il'in, K. K.; Cherkasov, D. G.; Yakusheva, S. A. Polythermal study of isopropyl alcohol salting-out from aqueous solutions with potassium chloride and bromide. Zh. Obshch. Khim. 1998, 68, 250-256.

(11) Garcia-Cano, J.; Gomis, A.; Font, A.; Gomis, V. Effect of temperature on the phase-separation ability of $\mathrm{KCl}$ in aqueous twophase systems composed of propanols: Determination of the critical temperature and extension of the results to other salts. J. Chem. Thermodyn. 2019, 136, 88-99.

(12) Greve, A.; Kula, M. Phase diagrams of new aqueous phase systems composed of aliphatic alcohols, salts and water. Fluid Phase Equilib. 1991, 62, 53-63.

(13) Ojeda Toro, J. C.; Dobrosz-Gómez, I.; Gómez García, M. Á. Sodium sulfate solubility in (water+ethanol) mixed solvents in the presence of hydrochloric acid: Experimental measurements and modeling. Fluid Phase Equilib. 2014, 384, 106-113.

(14) Hofmeister, F. Zur lehre von der wirkung der salze. Arch. Exp. Pathol. Pharmakol. 1888, 24, 247-260.

(15) Lyde, D. R. Handbook of Chemistry and Physics, 83rd ed.; CRC Press: Boca Raton, 2002.

(16) Thomsen, K.; Rasmussen, P.; Gani, R. Correlation and prediction of thermal properties and phase behaviour for a class of aqueous electrolyte systems. Chem. Eng. Sci. 1996, 51, 3675-3683.

(17) Thomsen, K.; Rasmussen, P. Modeling of vapor-liquid-solid equilibrium in gas-aqueous electrolyte systems. Chem. Eng. Sci. 1999, 54, 1787-1802.

(18) Chen, C.; Song, Y. Generalized electrolyte-NRTL model for mixed-solvent electrolyte systems. AIChE J. 2004, 50, 1928-1941.

(19) Gerlach, T.; Müller, S.; Smirnova, I. Development of a COSMORS based model for the calculation of phase equilibria in electrolyte systems. AIChE J. 2018, 64, 272-285.

(20) Thomsen, K.; C. Iliuta, M.; Rasmussen, P. Extended UNIQUAC model for correlation and prediction of vapor-liquid-liquid-solid equilibria in aqueous salt systems containing non-electrolytes. part B. alcohol (ethanol, propanols, butanols) - water-salt systems. Chem. Eng. Sci. 2004, 59, 3631-3647.

(21) Song, Y.; Chen, C. Symmetric electrolyte nonrandom two-liquid activity coefficient model. Ind. Eng. Chem. Res. 2009, 48, 7788-7797.

(22) Marcilla, A.; Olaya, M. M.; Serrano, M. D. Liquid-Vapor equilibrium data correlation: Part I. pitfalls and some ideas to overcome them. Ind. Eng. Chem. Res. 2011, 50, 4077-4085.

(23) Gmehling, J.; Onken, U.; Arlt, W. In Vapor-Liquid Equilibrium Data Collection. Aqueous-Organic Systems (Supplement 1); Kreysa, G., Ed.; Chemistry Data Series; DECHEMA: Frankfurt am Main, 1998; Vol. I, Part 1a.

(24) Kojima, K.; Tochigi, K.; Seki, H.; Watase, K. Determination of vapor-liquid equilibrium from boiling point curve. Chem. Eng. 1968, 32, 149-153.

(25) Gomis, V.; Ruiz, F.; De Vera, G.; López, E.; Saquete, M. D. Liquid-liquid-solid equilibria for the ternary systems water-sodium chloride or potassium chloride-1-propanol or 2-propanol. Fluid Phase Equilib. 1994, 98, 141-147. 